\title{
Exploring the Focus of Enterprise Informatization During Digital Transformation
}

\author{
Lin-Yu ${ }^{*}, \mathrm{GuQian}$ \\ Information Center, China Tobacco Fujian Industiral Co., Ltd, Xiamen, Fujian, China
}

\begin{abstract}
As an irreversible trend in nowadays manufacturing industry, digital transformation has put higher demands on enterprise's informatization. This paper reviewed how the focus changed for enterprise informatization in the manufacturing industry during each development stage, summarized the development trend for informatization in the industry, and put forward the three focuses of enterprise informatization during digital transformation. In a new historical stage, enterprises should focus their efforts on the following aspects: integrating informatization with lean management to optimize the value system as much as possible; building an integrated management model to achieve overarching control on informatization; realizing in-depth integration of informatization and industrialization to follow a path to new industrialization.
\end{abstract}

\section{Introduction}

The Communist Party of China Central Committee's proposals for formulating the 14th Five-Year Plan (2021-2015) for National Economic and Social Development and the Long-Range Objectives Through the Year 2035, as reviewed and approved at the fifth plenary session of the 19th CPC Central Committee, suggest that the nation should unswervingly build a manufacturing, quality, cyber and digital powerhouse, in order to promote advanced industrial bases, modernize industrial chains and improve economic quality and core competitiveness[1], which put higher demands on enterprise's informatization. After nearly four decades of reform and opening-up, the nation's manufacturing enterprises have equipped themselves with solid foundations for informatization. However, weak links still exist in aspects such as the economic benefits of informatization, its ability to drive smart manufacturing, and the coordination between the upstream and downstream industries.

Based on the abovementioned issues, this paper reviewed how the focus changed for enterprise informatization in the manufacturing industry during each development stage, summarized the development trend for informatization in the industry, and put forward the three focuses of enterprise informatization during digital transformation, namely, integrating informatization with lean management to optimize the value system as much as possible; building an integrated management model to achieve overarching control on informatization; realizing in-depth integration of informatization and industrialization to follow a path to new industrialization.

\section{Changes of focus in enterprise informatization during each development stage}

The eternal goals of enterprise informatization are to achieve business process reengineering, improve management efficiency, increase productivity and help enterprises gain the upper hand in fierce market competition. In the meantime, enterprise informatization is constantly restricted by the technical conditions of the times, which requires continuous investment flows to support the upgrade of enterprise management processes, the optimization of production processes and the transformation of the industrial chains in faster and better ways.

\subsection{Infrastructure construction and single applications during the Pre-Internet Era}

During the 1980s and 1990s, at the very beginning of enterprise informatization, internet applications had not yet taken shape, and single applications represented the leading demands for informatization. By developing relatively simple software (SIS or MIS) to handle management issues concerning personnel, finance and other aspects, the digital electric power plants in the $1980 \mathrm{~s}$, for instance, single applications provide enterprises with a digital platform to control and manage their comprehensive optimization [2].

\footnotetext{
* Corresponding author: ly10082@fjtic.cn
} 


\subsection{The construction of new comprehensive systems during the Internet Era}

In the first ten years of the 21st century, as technology advanced, automation was gaining speed inside enterprises. In response to the gradually expanding business needs, enterprises began to construct integrated information systems with stronger functions. Such information systems were often seen in specific business areas, such as the automated sorting systems in the logistics industry, which could significantly improve the efficiency and process visibility of package distribution [3].

\subsection{Overall development and integrated improvement during the Mobile Internet Era}

Since 2010, after years of informatization, enterprises have built a great number of business systems in response to their business needs, which solved the problem of business process informatization to a certain extent. However, data barriers still exist between these systems. Therefore, system integration structures such as ESB and SOA had come into being. Enterprises started to realize the key role played by superior top-level designs and try to introduce information consulting into the planning of future informatization. At the same time, commercial database technology gradually became fullfledged. The focus of enterprise informatization had been shifted to the management of data storage applications, while the building and management of databases became an important task in informatization. The booming of consumer-level mobile Internet applications gave birth to new demands for corporate management and information transmission in the mobile ends [4-6]. Enterprises were paying more attention to building their talent teams, cultivating their own professional and versatile talents.

\subsection{Synergy and innovations during digital transformation}

Since 2015, as Internet giants like Alibaba and Tencent marched towards opening up the entire industry chain, the more agile, responsive and personalized product sales thinking was transformed due to the extension of ecommerce supply chains, which posed a strong impact on manufacturing enterprises. In terms of the digitalization process, enterprises started to create digital applications encompassing the entire process and cycle to avoid homogenized competition. Driven by innovation and the pursuit of new technology, methods, personality and high-quality, they successfully upgrade their products and discover new driving forces for their development.

During this period, Alibaba reviewed its successful practices in transforming from "sharing service platform" to "business middle platform" and "data middle platform," and released a design to transform an enterprise's IT architecture based on the "middle platform strategy." The Internet giant provided a brand- new informatization solution for manufacturing enterprises that are long stuck in long delivery times, high operation and maintenance costs, isolated data island and the problem repeated construction [7-9].

On the other hand, the rise of artificial intelligence and 5G technology has significantly expanded the application scenarios of manufacturing enterprises in the field of industrial Internet. Questions like "how to take advantage of the informatization's roles as the 'multiplier' for enterprise economic growth, 'converter' for their development mode and 'booster' for industrial upgrading" are gaining attention in enterprise informatization. They also bring unprecedented opportunities for enterprise informatization to be upgraded into value system optimization. Informatization has become an important pillar for realizing smart manufacturing.

\section{Characteristics of Informatization in Manufacturing Industry}

Informatization has been supporting the rapid development of the manufacturing industry. On the whole, it presents the characteristics of transforming from single applications to multi-business integration, from full outsourcing to all staff participation, and from amateur to professional.

\subsection{Informatization: from single applications to multi-business integration}

The informatization in the manufacturing industry started from separate application points. Most enterprises went into the business by purchasing computers and installing applications. Following such attempts, they tried to promote them on the enterprise level, transforming single business applications to multibusiness integration, from applications by a single enterprise to the coordinated operation of upstream and downstream industries.

However, the point-to-area informatization model tended to cause problems such as separate business domains, and excessive and scattered exploration directions, which put higher demands for integrated management and control capabilities. So how to manage the enterprise informatization from a top-down approach, effectively grasp the direction of exploring new technologies, and improve the input-output ratio serve as major challenges for enterprises during digital transformation.

\subsection{Information technology services: from full outsourcing to all staff participation}

At the dawn of informatization, due to the shortage of related talents, enterprises tended to outsource the entire informatization process of design, implementation, operation and maintenance. As informatization's support for enterprise development became stronger, enterprises invested more resources, such as funds and talents, into the area, and created an informatization model led by 
professional IT departments and participated by multiple business departments. They actively participated in the implementation, development, operation and maintenance of information systems, forming effective management over the third-party suppliers. Hence their information management has been continuously improved.

Digitalization allows us to better manage our businesses. Only the experts on business digitalization with related professional skills can transform data into usable information to support the decision-making of the enterprises. In Internet-based enterprises, over $50 \%$ of the data service development is conducted by analysts in each business domain. In terms of the manufacturing industry, this trend has a significant impact on the development of information technology. If enterprises want to open up the end-to-end value chains, become data-driven and empower corporate innovations in their core businesses such as R\&D, manufacturing, marketing, operations and services, they have to implement IT services and concepts down to each post and encourage every employee to participate in the informatization process.

\subsection{Team building: from amateur to professional}

At the very beginning of corporate informatization, most enterprises had not yet set up their own IT department. Their IT teams were managed by functional departments such as integrated management and corporate management departments. As informatization progressed in the whole society and the nation stepped up the training of IT talents, enterprises are now able to establish their specialized IT departments and form a complete system of job descriptions based on the needs of informatization. Their IT teams consist of young and professional talents with a clear division of responsibilities. They have experts in project management, hardware maintenance, software development, system operation and maintenance and network security. IT jobs become more diversified and more professional talents are needed.

On the other hand, enterprises are also facing many challenges when building their IT teams. For instance, the IT departments in the manufacturing industries cannot afford the salaries given by those in the Internetbased enterprises, resulting in difficulty in employee recruiting and outflow of talents. Software development and operations are more likely to be outsourced to external suppliers, resulting in outdated knowledge and skills of the IT teams and their lack of core competitiveness. The IT teams seldom exchange information with business departments to gain on-theground experience, and therefore, enterprises are still in desperate need of high-quality, versatile talents who are familiar with information technology and the company's business at the same time.

\section{Development Paths for Enterprise Informatization during Digital Transformation}

Digital transformation refers to the process in which enterprises adapt to a new round of technological revolution and industrial changes, and the process of optimizing, innovating, and reconstructing their value systems through systematic enterprise reforms. By deeply integrating manufacturing industries with advanced information technologies such as $5 \mathrm{G}$, cloud computing, big data, artificial intelligence, and blockchain, informatization is bound to continuously elevate enterprises' capabilities to survive and thrive in the digital era.

\subsection{Path of integrating informatization with lean management}

The theory of lean management was put forward by Womack in 1995 when he was reviewing the lessons learned in Toyota. The theory has been proved to have profound impacts on the manufacturing industry. As pointed out by Womack, the five principles of lean management include defining value, mapping the value stream, creating flow, using a pull system, and pursuing perfection [10]. The concept of lean management provides significant references for solving the dilemmas of repeated construction and resource waste during enterprise informatization, and realizing the essential tasks of enterprise digital transformation, namely the optimization, innovation and reconstruction of the value system.

Only by accurately defining the business values, can we truly understand the complicated process of the business departments, and allow the IT and business departments to complement each other. Only by digging deep into the entire value stream of the enterprise, can we avoid the errors of pursuing informatization projects from single application points, and can we make it clear that during enterprise informatization, we must come up with a global vision and a complete construction route from the perspective of system engineering. If we want to realize the value of enterprise informatization, we have to use IT to reengineer the business process of the enterprise. By identifying the "disruptions, blockages and fragmentations" of the current processes, we can build an information system to form synergy among various business domains, rather than simply copying the old processes. When we look back upon the practices of Alibaba concerning its Middle Platform Strategy, Business Middle Platform and Data Middle Platform, it is easy to find that enterprise-level Middle Platform construction stands as an embodiment of informatization integrated with lean management.

Digital transformation poses a long-term, complicated and arduous challenge for enterprises. If an enterprise can systematically review its entire value stream, and introduce lean management concept into the stages of informatization such as the planning, designing, model selection, procurement, system construction, 
operation and maintenance, and update, etc., it can effectively reduce construction costs, elevate construction efficiency and optimize the value system of enterprise informatization as much as possible.

\subsection{Path of building integrated management models}

Digital transformation spurs manufacturing enterprises to conduct fundamental, strategic and overall reforms on their production or business models. In terms of management models, systematic solutions and governance systems are needed to provide organizational support and mechanism guarantees for the informatization during digital transformation.

Only by standing at the strategic height and overlooking the enterprise as a whole, coordinating various aspects of informatization to achieve unified planning, design, architecture standards, project management, operation and maintenance, can the informatization management model be transformed from "loose coupling" to "strong controlling" to realize the overall management on informatization. Only in this way can we pool efforts from the whole enterprise, extend its business to both the upstream and downstream of the industrial chain, and help enterprises to move ahead steadily on the road of digital transformation. In terms of concrete management forms, enterprises need to establish an integrated management model including "digital transformation strategy, policy, project, and performance." They need to conduct hierarchical management over projects such as consulting services, software procurement, hardware installment and system development. The division of responsibilities also needs to be clarified to streamline the management process and improve decision-making efficiency.

Under the integrated management model, enterprises should make clear the directions, goals and priorities of their digital transformation, and formulate plans for future production or business model and the blueprint for industrial ecology development from a strategic level. Through such measures, they can form a series of informatization projects and create the enterprise's core competitiveness during digital transformation. In the construction phase, enterprises use project group management to improve collaboration efficiency, and play the role of coordination among a large number of informatization projects. Taking into account all parties' concerns, they allocate resources and formulate reasonable plans to ensure the steady progress of digital transformation. In the operation phase, the organizational models will be continuously updated. Technological and management innovations will form synergy to optimize business process design, adjust and reconstruct organizational mechanisms and improve governance systems.

\subsection{Path of deeply integrating informatization into industrialization}

For manufacturing enterprises that want to boost their informatization, it is sensible for them to use IT to promote industrial manufacturing upgrading, advance the integration of informatization and industrialization by taking advantage of some cutting-edge technologies such as Internet of Things, cloud technology, big data, and VR/AR, and by this create a new path leading to industrialization.

Industrial Internet is a key infrastructure supporting the enterprise's integration of informatization and industrialization. For a long period of time, industrial enterprise data has been highly fragmented, with highly structured business data, semi-structured data such as design drawings, technical documents, and time series data for production lines, equipment and logistics processes, etc. Such data are usually highly correlated. However, they tend to be collected, processed and stored in different ways [11-12]. Only by establishing a mature Industrial Internet, can we realize real-time and efficient aggregation, analysis and application of complex industrial data, promote reengineering of the industrial production process and support the transformation and upgrading of industrial chains.

During the "13th Five-Year Plan" period, China has basically finished building the foundation and framework for its industrial Internet network, platform and security system. The total value of the industry reached 3 trillion yuan, with over 250,000 industrial Internet applications being registered. It is estimated that the number of industrial Internet applications will reach 1 million by the year 2025. Industrial Internet applications grant free access to enterprise data, which has redefined the life cycle of manufactured products. In terms of product R\&D, the digital design, simulation and optimization of the product's entire life cycle based on digital technology helps enterprises conduct R\&D digitally to realize product innovations [13]. In terms of product manufacturing, digital twin and AR-based technological applications help enterprises transcend time and space barriers to realize full perception and precise control of production processes and sites and drive flexible production. In terms of product services, with the help of wireless interconnection technology, product operation data can be uploaded to the industrial Internet platform so that enterprises are able to provide customized after-sales services based on data analysis and improve their capabilities in providing extended services. In terms of product quality assurance, the source-tracing system based on blockchain technology helps users quickly and effectively inquire about the origin of the product and where the processing takes place to ensure the product's quality and safety.

Smart manufacturing is the main direction for industrial upgrading integrating informatization and industrialization. With exacerbating shortage of resources and the rising prices of labor and land, China will inevitably face the challenge of the aging population, which will profoundly impact the optimization, transformation and upgrading of manufacturing 
enterprises. From January to August 2020, China's industrial robot production grew despite the rampaging global COVID-19 pandemic to 137,000 sets, a year-onyear increase of $13.9 \%$. Loaded with simple programs, the new generation of robots can perform various tasks and can be quickly assigned to different posts. At the same time, with the rapid development of artificial intelligence, the new production line quality management solutions, as represented by computer vision technology, pose strong impacts on laborintensive enterprises that heavily rely on manual quality inspection such as steel, textile and semiconductor manufacturers [14-15]. As technologies such as the Internet of Things, 5G, and edge computing grow more mature, in the future manufacturing enterprises, devices like industrial robots, $\mathrm{AGVs}$, intelligent monitors and mobile terminals will be connected to the edge-side industrial Internet platform to enable real-time collaboration during the smart manufacturing processes, with an aim to create a new form of production synergy.

The road to informatization-industrialization integration is a way to open up enterprises' end-to-end value chains and make good use of their industrial data assets. Based on the Industrial Internet, informatization empowers innovations in core business processes such as product R\&D, manufacturing, commodity logistics, product sales and services. By creating smart manufacturing applications, enterprises can stand out among industrial competitors in the new era.

\section{Conclusions}

As the digital transformation of the manufacturing industry became an irreversible trend of the time, the model changes brought by the integration of informatization and industrialization are bound to generate more benefits for enterprises. Industrial changes will also promote evolution of corporate management models.

As new generation IT is tremendously influencing manufacturing enterprises, information technology will certainly be integrated into enterprises' DNA. In a new historical stage, if enterprises want to digitally transform themselves, they have to pivot their work to innovations besides merely relying on low production costs. All these, however, cannot be done without their staff. Therefore, it is essential to raise employees' awareness of digitalization and improve their professional skills. Only by constantly updating their knowledge, taking newly-developed methods and tools, can the whole enterprise move towards digitalization, informatization and intelligence, tapping into the infinite possibilities in the future.

\section{References}

1. Leading Party Group of the Ministry of Industry and Information Technology of the PRC. Qiushi. J. E 22 (2020)

2. Hou Z., Pan G. Electric Power. J. E 38(2), 78-80 (2005)
3. Tian J. et al. Chinese Journal of Scientific Instrument. J. E 27(z3), 1875-1877 (2006)

4. Liu J. Enterprise Economy. J. E 5, 88-90(2011)

5. Jin P. et al. Chinese Journal of Computers. J. E 9, 1777-1795 (2015)

6. Zhao Z. China Industrial Economics. J. E 10, 146160 (2015).

7. Zhong H. Transformation of Corporate IT Architecture: Middle Platform Strategic Thinking, Architecture and Practice of Alibaba (China Machine Press, Beijing, 2017)

8. Deng Z. Big Data Innovation: The Cloud Data Middle Platform of Alibaba (Publishing House of Electric Industry, Beijing, 2018)

9. Chen X. Et al. Middle Platform Strategy: Construction and Digital Business (China Machine Press, Beijing, 2019)

10. James P., Daniel T. Lean Thinking: Banish Waste and Create Wealth in Your Corporation (Publishing House of Electric Industry, Beijing, 2011)

11. Qi W. et al. Modern Electronics Technique. J. E 40(3), 153-156 (2017)

12. Shi Z. Et al. Integrating Data and Things: Digital Enterprise Reconstructed by Industrial Internet (Publishing House of Electric Industry, Beijing, 2018)

13. Li Y. Automation and Instrumentation. J. E 2, 189192 (2020)

14. Wu Z. et al. Journal of Computer-Aided Design and Computer Graphics. J. E 30(12), 2262-2270 (2018)

15. Dai X., Chen H., Zhu C. Surface Technology. J. E 49(10), 362-371 (2020) 